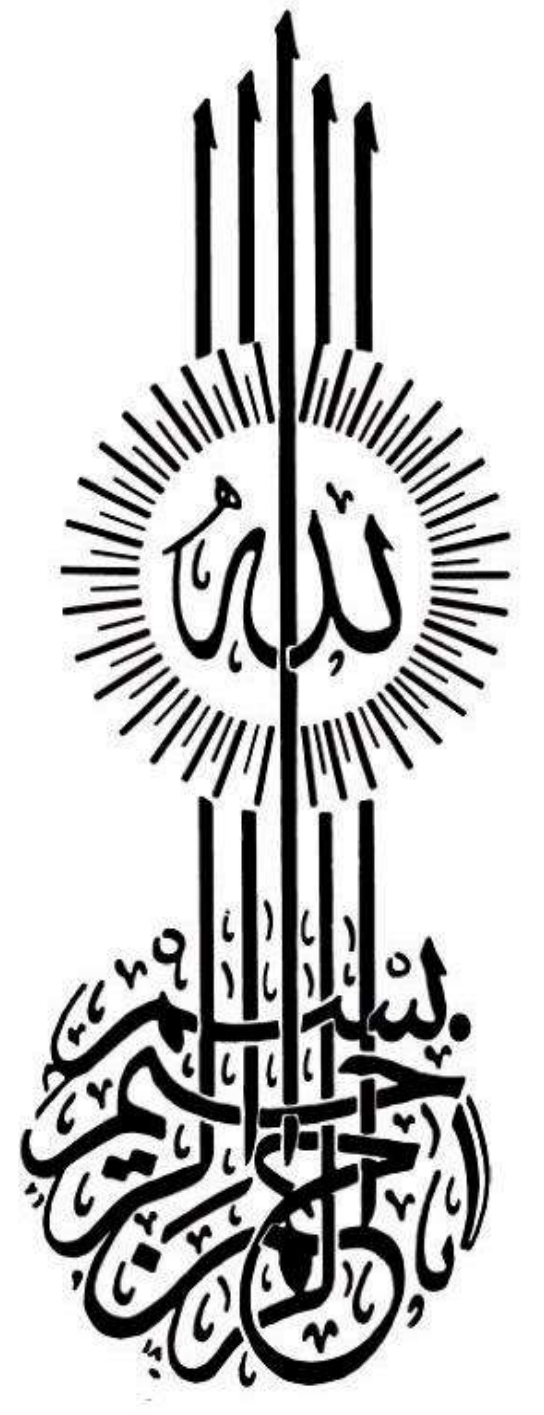

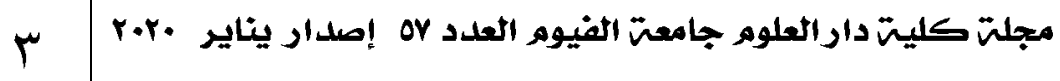




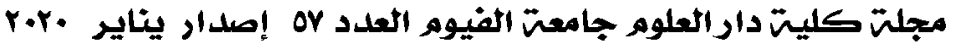




\section{مقلدمة الحلد}

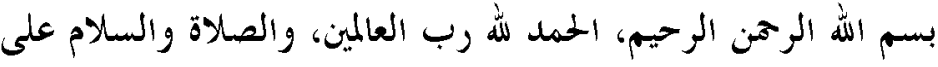

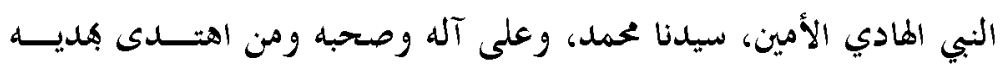
والتزم بنهجه وتمسك بسنته إلى يوم الدين، وبعد:

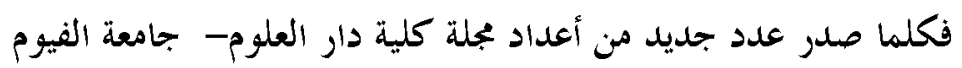

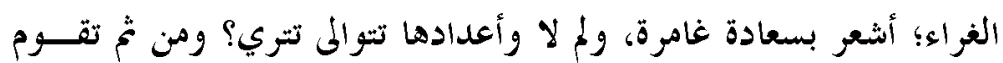

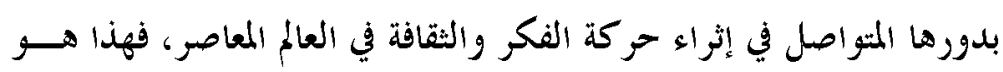

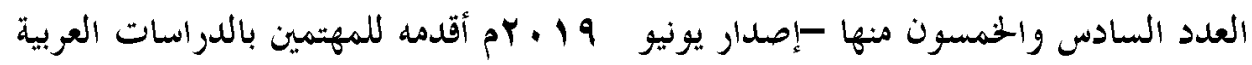

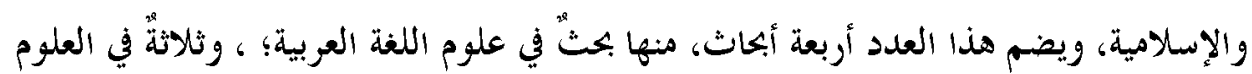

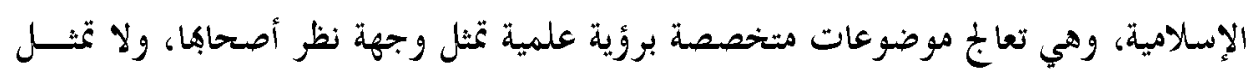
بحال من الأحوال وجهة نظر إدارة البجلة.

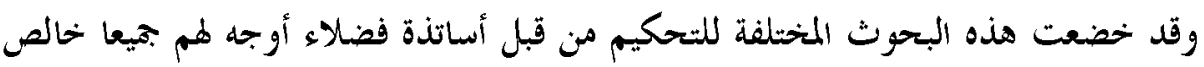

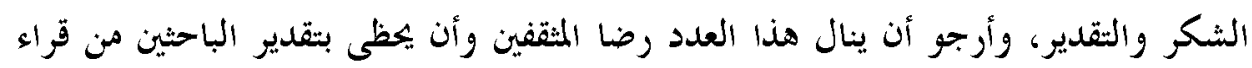

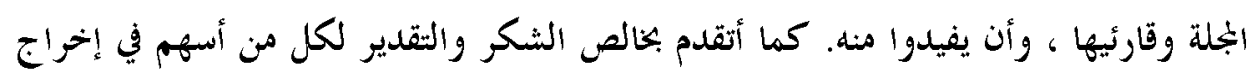

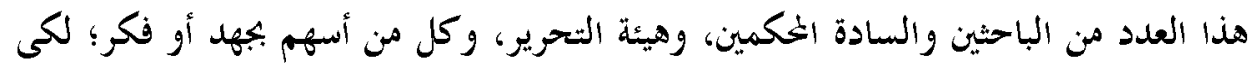
يخرج هذا العدد بهذا الرونق والتميز. وختامًا تتمنى إدارة الجُلة أن يحقق هذا العدد أهدافه المرجوة، وأن تسهم البجلة في النهوض

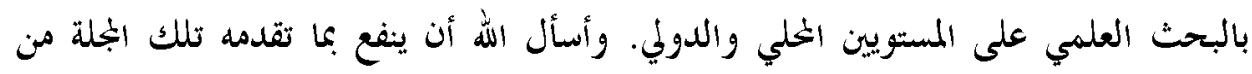

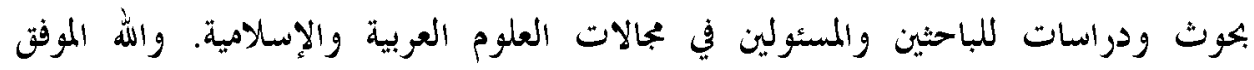

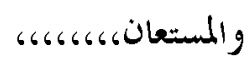

\section{رئيس مجلس إدارة المجلة}

رئيس القحريد

مميل الكيلية

أ.د/ إمام محمد عبد الثمتاح 


\section{مجلس التحرير}

رئيس التحرير

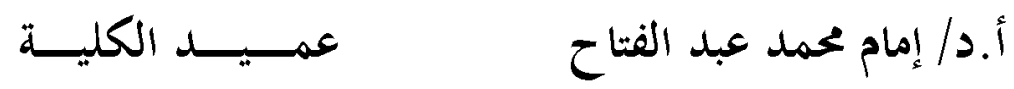

نائب رئيس التحرير

أ.د / محمد حامد عجيلة وكيل الكلية لشئون الدراسات العليا والبحوث

الأعضـــاء

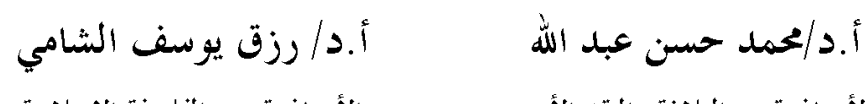

الأستاذ بقسم البلاغة والثقد الأدبي الأستاذ بقسم الفلسفة الإسلامية

القائم بتسبييز أعمال

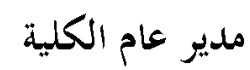

أ أ زينب محمود السيد

\section{سكرتاريت المجلة}

القائم بعمل رئيس قسم

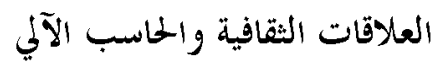

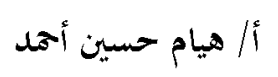

\section{الإجاس الاستشاري للمبحلة}

\begin{tabular}{|c|c|}
\hline كلية دار العلو. فريد عوض حيدر جامعة الفيوم & كلية دار العلوم جمامد حسن عبد الله الفيوم \\
\hline كلية دار العلوم - جحمد فتمعة القاهرة & 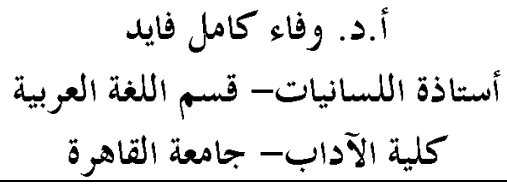 \\
\hline قسم الثريعة الإسلامية - حقموق بحمد بنى سويف علامة & كلية دار العلوم جاح عبد المعز العشيرى الفيوم \\
\hline كلية الآداب - جامعة أحد الشربيني & كلية دار العلوم - - جامعة القيد الجليند اهرة \\
\hline
\end{tabular}

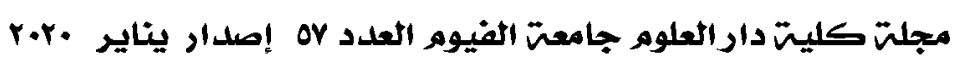




\begin{tabular}{|c|c|}
\hline كلية الآداب مع - جامعة بن سعيد العدواين & 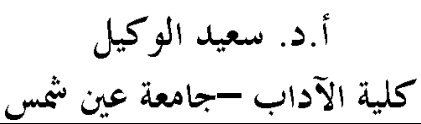 \\
\hline واللفات ـ جأدعة يوسف وغليسي كلية الآداب & كلية الآداب سليمان على الثطبي \\
\hline
\end{tabular}

\section{قواعد النشر بالمبلة}

بجلة كلية دار العلوم مجلة علمية محكمة ثنشر البحوث العلمية الثي ثتسم بالجددة في اللغة العربية والعلوم الإسلامية، ويشترط للنشر في هذه الجلة ما يأبي:

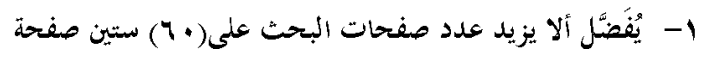

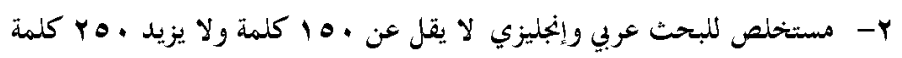

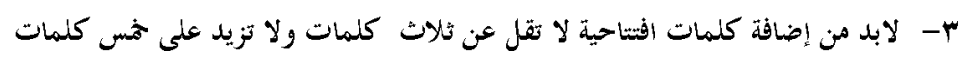
צ- ألا يكون قد سبق نشره أو نشر مقتطفات مثنه.

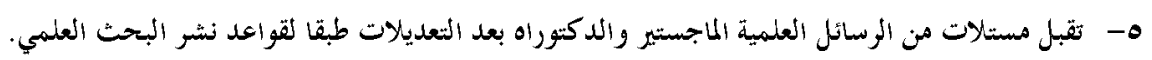
أ أ- أن تكون مادثه العلمية موثقة طبقا للنظام الآيتي:

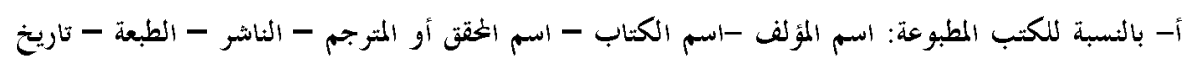
النشر - رقم الجزء والصفحة.

ب- بالنسبة للمخطوطات: اسم المؤلف -اسم الكتاب - مكان المخطوطة - رقمه - ـ رقم اللوحة أو الصفحة.

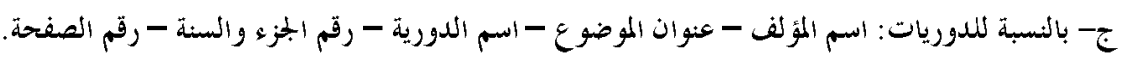

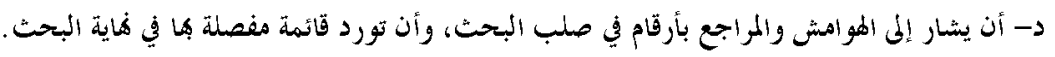

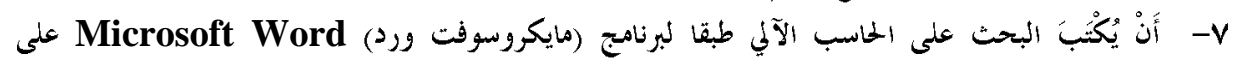

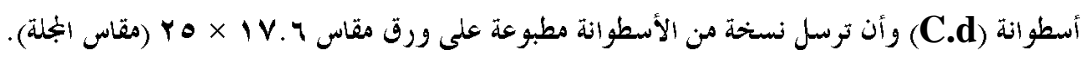

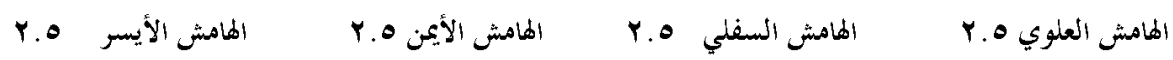

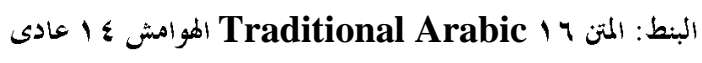

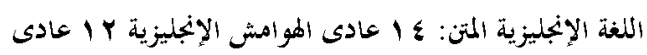
^- يرسل البحث مع رسوم الثحكيم الثتي تقدر على الثحو الثنالي:

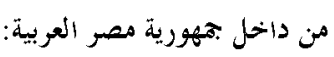

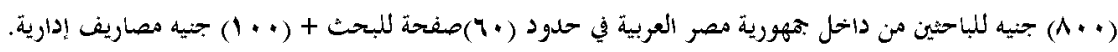

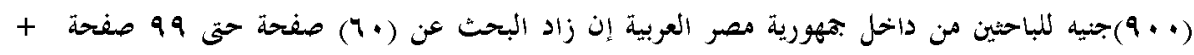

$$
\text { من خارج جمهورية مصر العربية: ( + ( جنيه مصاريف إدارية. }
$$

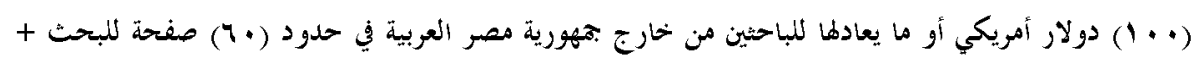

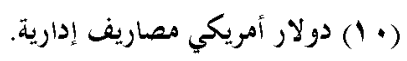

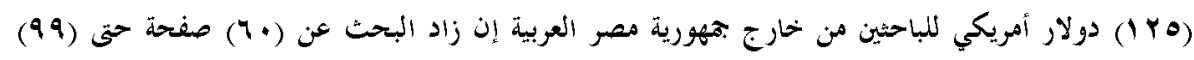




$$
\begin{aligned}
& \text { صفحة + ( • (1) دولار أمريكي مصاريف إدارية. } \\
& \text { 9- بعد قبول البحث يقوم الباحث بدفع رسوم النشر وهي كالالي: } \\
& \text { من داخل بمهورية مصر العربية: }
\end{aligned}
$$

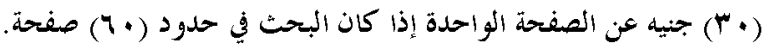

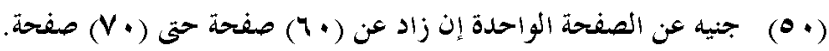
(V•)

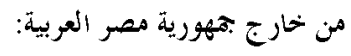

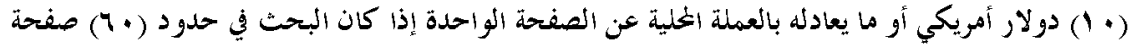

$$
\text { ما زاد عن (· (4) صفحة يكون حسابه كالآيت: }
$$

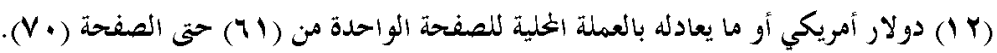

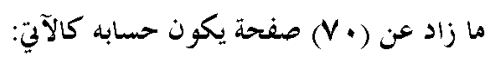

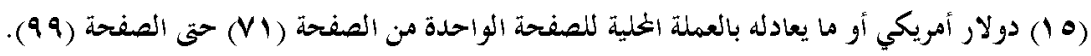

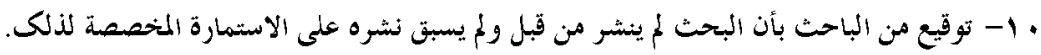

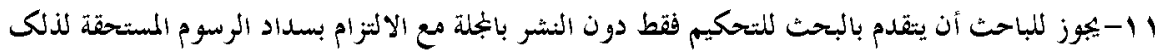

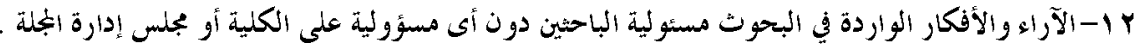

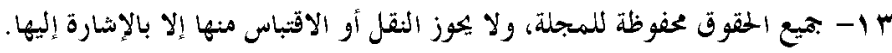

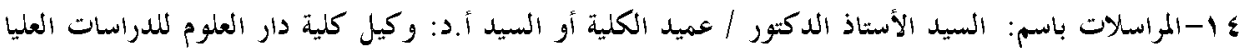

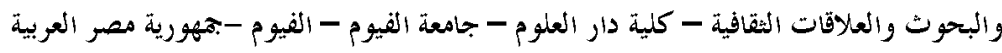

$$
\begin{aligned}
& \text { من داخل جمهورية مصر العربية }
\end{aligned}
$$

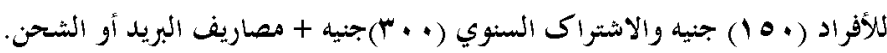

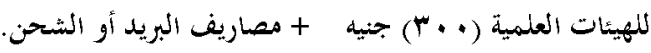

$$
\begin{aligned}
& \text { من خارج جمهورية مصر العربية }
\end{aligned}
$$

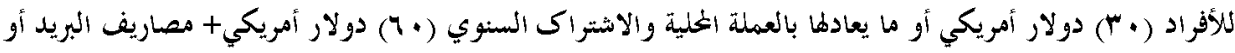

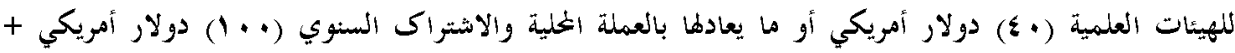

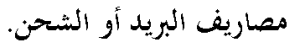

$$
\text { ترسل الاشتراكات مقدها باسم: }
$$

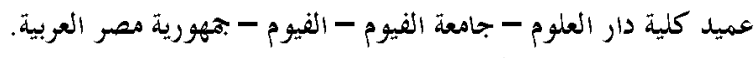

وسائل الاتصال بالجنة

emdar@fayoum.edu.eg اليريد الإليكتروبي: dodar@fayoum.edu.eg البريد الإليكتروبي: الإنكروي:

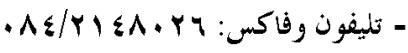

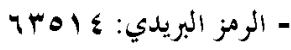

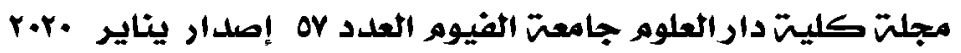

